\section{Public Health Genomics}

Public Health Genomics 2012;15:1-10

DOI: $\underline{10.1159 / 000325746}$
Received: April 19, 2010

Accepted after revision: February 16, 2011

Published online: May 3, 2011

\title{
HER2 Evaluation and Its Impact on Breast Cancer Treatment Decisions
}

\author{
K.A.B. Goddard S. Weinmann K. Richert-Boe C.Chen J.Bulkley C. Wax
}

The Center for Health Research, Kaiser Permanente Northwest, Portland, Oreg., USA

\section{Key Words}

Genetic $\cdot$ Herceptin $\cdot$ Translation $\cdot$ Trastuzumab

\begin{abstract}
Background: Eighteen to twenty percent of breast cancer tumors show abnormal amplification of the Human Epidermal growth factor Receptor 2 (HER2) gene and increased expression of the associated protein. HER2 amplification is associated with rapid tumor proliferation and shorter disease-free and overall survival. Because women with HER2 amplification are more likely to benefit from treatment with the drug trastuzumab, testing for HER2 is recommended to guide therapy. However, little is known about use of HER2 testing in real-world settings. This study examined uptake, use, appropriateness of HER2 testing, and the relationship between HER2 test results and treatment decisions. Methods: We assessed electronic data from 3,634 patients with invasive breast cancer diagnosed from 1998 to 2007 in a large integrated health system. We collected data on patient and tumor characteristics, HER2 testing status, test results, and trastuzumab treatment. Results: From 1998 to 2000, the percent of patients who underwent HER2 evaluation increased from 12 to $94 \%$; $<3 \%$ of women with ductal carcinoma in situ, for whom HER2 testing is not recommended, were tested. Trastuzumab use increased 5-fold after 2004, when guidelines expanded to include recommending adju-
\end{abstract}

vant treatment for early-stage breast cancer in addition to metastatic treatment. Ninety-five percent of women receiving trastuzumab had a positive HER2 result. After 2004, 55\% of women with invasive breast cancer and overexpression of HER2 received trastuzumab treatment; this ranged from $44 \%$ of women with localized breast cancer to $80 \%$ of women with distant metastatic disease. Conclusions: These findings illustrate appropriate and effective implementation of a HER2 testing strategy in a managed care setting.

Copyright $\odot 2011$ S. Karger AG, Basel

\section{Introduction}

Breast cancer is the second-most deadly malignancy in women [1] and accounts for one-fourth of all expected new female cancer cases. In 2009, about 92,000 American women were diagnosed with breast cancer and over 40,000 are expected to die of the disease [2]. Many women with early-stage breast cancer are offered adjuvant chemotherapy to prevent recurrence. While new geneticbased technologies that can help predict cancer recurrence or treatment response present exciting opportunities for improving outcomes, little is known about how such technologies are being incorporated into practice and whether they are being used appropriately to make treatment recommendations $[3,4]$.

\section{KARGER}

Fax +41613061234

E-Mail karger@karger.ch

www.karger.com
(C) 2011 S. Karger AG, Basel

Accessible online at: www.karger.com/phg
Katrina A.B. Goddard, $\mathrm{PhD}$

The Center for Health Research, Kaiser Permanente Northwest

3800 N. Interstate Avenue

Portland, OR 97227 (USA)

Tel. +1 503335 6353, E-Mail katrina.ab.goddard@ kpchr.org 
Human Epidermal growth factor Receptor 2 (HER2) is a gene that influences cell growth, division and repair; a normal cell has 2 copies of HER2. About $18-20 \%$ of breast cancers have amplification of this gene [5-7], which is associated with rapid tumor proliferation, shorter disease-free survival and poorer overall survival [810]. Trastuzumab (Herceptin ${ }^{\circledR}$, Genentech Inc., San Francisco, Calif., USA) acts by targeting production of the HER2 protein to prevent the growth of HER2-positive cancer cells, thereby reducing recurrence of disease and reducing mortality [11-15]. However, trastuzumab only benefits women with HER2 gene amplification, is expensive (USD 44,000-65,000 per year $[16,17]$ ) and can be cardiotoxic [18]. Therefore, selecting appropriate patients to receive trastuzumab is vital.

Currently, 2 types of tests are approved by the U.S. Food and Drug Administration for determining HER2 status. The immunohistochemistry (IHC)-based test (e.g. DAKO HercepTest; Ventana Pathway) measures production of HER 2 protein by the tumor. Test results are ranked as $0,1+$ (negative), $2+$ (equivocal), or $3+$ (positive). The fluorescence in situ hybridization (FISH) test (e.g. Vysis PathVysion; Ventana INFORM HER2 probe) quantifies the number of copies of the HER2 gene in tumor cells. A positive HER2 test is defined as IHC $3+$ and, to a lesser extent, IHC $2+[19-21]$ or a HER2:CEP17 ratio >2 [22, 23]. While some reports suggest that FISH technology more accurately predicts response to trastuzumab than IHC technology [24], a recent summary report indicates that the 2 tests are comparable if careful validation testing is performed [25]. HER2 testing may also predict response to several systemic therapies, including anthracyclines and resistance to endocrine therapy, although the evidence is not always consistent [10, 26-45].

The Food and Drug Administration initially approved trastuzumab in 1998 for use in patients with metastatic breast cancer. In November 2006, it approved trastuzumab as an adjuvant therapy for women with lymph nodepositive and HER2-positive breast cancer [12-14]. Trastuzumab is not recommended for patients with a positive HER2 test result if they have cardiovascular risk factors. A joint guideline from the American Society of Clinical Oncologists (ASCO) and the College of American Pathologists (CAP) state that HER2 testing should be performed for all invasive breast cancers regardless of lymph node disease status [25], and the National Comprehensive Cancer Network (NCCN) also endorsed HER2 testing [46-50].

Despite these well-developed, evidence-based practice guidelines, however, little research has been done on this test in real-world settings. In particular, Phillips [3] indicated that little is known about what percentage of patients are tested for HER2, which testing methods are used, whether patients are retested to confirm indeterminate results, and how many patients with negative or equivocal results receive trastuzumab.

Our study addressed this knowledge gap by evaluating utilization and treatment patterns associated with HER2 testing for patients with breast cancer in an integrated healthcare delivery system. We studied a cohort from this health plan with more than 12 years of electronic medical records and other data sources. We documented the uptake and use of HER 2 testing and evaluated whether testing was being done appropriately according to professional guidelines. We considered the use of IHC versus FISH testing and trastuzumab prescriptions in the context of the HER2 test result. This study is one of the largest and most comprehensive studies illustrating the realworld use and impact of HER2 testing.

\section{Subjects and Methods}

\section{Study Population}

Study participants were patients at Kaiser Permanente Northwest (KPNW), an integrated healthcare delivery system serving more than 470,000 members in Oregon and Southwest Washington. KPNW's members are demographically representative of the coverage area in terms of the age, gender and racial or ethnic distribution, and include about $20 \%$ of the area's population. Medicare members represent about $12 \%$ of KPNW's total membership. Members over 65 represent $12.8 \%$ of total membership, $2 \%$ are below $200 \%$ of the federal poverty level and $13 \%$ are minorities. We identified women with a primary diagnosis of breast cancer through KPNW's tumor registry. Women were eligible for the study if they were diagnosed with their first primary breast cancer between January 1, 1998 and December 31, 2007 and did not have missing data for tumor stage at diagnosis. We required that participants receive their diagnosis and initial treatment at KPNW. KPNW patients are treated at 5 area hospitals, and there are currently 10 oncologists on staff, although there were changes in staff over the 10 -year study period.

The Institutional Review Board at KPNW approved this study and did not require written informed consent. The Oregon Genetic Privacy law requires health care providers to notify patients that any specimens or health information will be available for anonymous or coded genetic research unless the person 'opts out'. About 13\% of KPNW's membership has opted-out, and these individuals were excluded from this study.

\section{Data Collection}

We abstracted electronic data on patient characteristics, tumor characteristics, HER2 testing status, test results for FISH and IHC separately, and trastuzumab treatment. The centralized tumor registry contains information on all cancers diagnosed at 
KPNW since 1960, and survival data is continuously updated. A trained abstractor keys items directly into the registry for each identified tumor. The pharmacy database records all prescriptions dispensed by KPNW outpatient pharmacies and includes date of dispensing, dose, prescribing physician, and unique codes using standard nomenclature to identify each drug.

\section{HER2 Genetic Testing}

All data used in this study are derived from testing that occurred as part of routine medical care provided by KPNW clinicians. Between 1998 and 2000, KPNW implemented an internal practice guideline of systematic screening for all women diagnosed with invasive breast cancer. According to this protocol, IHC is used as the initial HER2 test, followed by FISH testing to clarify or confirm equivocal or positive IHC findings.

IHC testing for HER2 was conducted by the KPNW regional laboratory using the HercepTest (Dako, Carpinteria, Calif., USA) and was classified as negative ( 0 or $1+$ ), equivocal $(2+)$ or positive (3+). FISH testing for HER2 was performed by Quest Diagnostics using the Vysis PathVysion test (Abbott Molecular, Abbott Park, Ill., USA) and was classified as negative (HER2/CEP 17 ratio $<1.8$ ), equivocal (HER2/CEP 17 ratio between 1.8 and 2.2) or positive (HER2/CEP 17 ratio $>2.2$ ). The standard protocol at KPNW changed in October 2007 to make FISH testing (performed at Quest Diagnostics) the initial HER2 test. For all cases with equivocal (1.8-2.2) FISH results, and for known grade 3 tumors with negative FISH results, IHC testing was also performed by Quest Diagnostics.

\section{Chart Abstraction}

Following the initial analysis of tumor-registry data, a single abstractor manually checked a sample of data points in the categories described below against the electronic medical record using standard data collection forms. Abstracted variables included IHC and FISH test results, date of test, stage of disease at diagnosis, lymph node involvement, tumor size, and trastuzumab use. For training, we developed instructions and a set of 'practice' charts that were scored by 2 study abstractors and compared [51]. Abstraction forms were entered into an electronic database using double data entry to ensure accuracy. Two reviewers discussed unexpected values to resolve issues.

We abstracted charts in 7 categories: (1) patients with a diagnosis of noninvasive breast cancer who nevertheless received HER2 testing ( $\mathrm{n}=11)$ after 1999; (2) patients with a diagnosis of invasive breast cancer who did not receive HER2 testing $(\mathrm{n}=154)$ after 1999; (3) patients who received FISH testing, but not IHC testing, after $2004(\mathrm{n}=93)$; (4) patients with a negative IHC test result that was confirmed by FISH after $2004(\mathrm{n}=87)$; (5) patients with an equivocal IHC test result that was not confirmed with FISH after $2004(n=69)$; (6) patients who received trastuzumab, but did not have a positive HER2 result $(\mathrm{n}=26)$; and $(7)$ HER2positive patients with distant metastatic or regional (after 2004) breast cancer who did not receive trastuzumab ( $\mathrm{n}=13$ and 21 , respectively). We verified findings in a random subset of patients for each category $(n=50$; except categories with fewer than 50 observations).

\section{Statistical Methods}

Patients were classified as receiving trastuzumab if any of the following national drug codes were in the pharmacy records after their date of diagnosis: 50242013460, 50242013468, 50242005656, 63552047001 , or if procedure code J9355 was in the procedures database. Lymph node status was dichotomized into positive (one or more positive nodes) or negative. We used SEER staging criteria [52] to define noninvasive breast cancer as patients diagnosed with ductal carcinoma in situ (DCIS) and invasive breast cancer as patients diagnosed with localized, regional or distant-metastasis breast cancer. All analyses, including descriptive statistics and summaries, were produced using $\mathrm{R}$ (version 2.6.2; R Foundation for Statistical Computing, www.r-project.org).

\section{Results}

\section{Pattern of HER2 Test Utilization}

There were 3,623 women who met the criterion of a primary breast cancer diagnosis during 1998-2007 (table 1). We excluded 31 women because of missing tumor registry data on cancer stage at diagnosis, a critical variable. Of the remaining women, about 538 (15\%) had a diagnosis of DCIS or noninvasive breast cancer, and 3,054 (85\%) had invasive breast cancer.

We defined women as 'evaluated' for HER2 if they received either IHC or FISH testing. Overall, 69\% of the study population was evaluated for HER2. However, this summary statistic obscures critical differences over time and by disease stage (fig. 1). First, according to clinical guidelines, the $15 \%$ of women with noninvasive breast cancer are not recommended for HER2 testing. In this group, only $2.5 \%$ received HER 2 testing, and the proportion remained consistently low over the entire study period. Of those with invasive breast cancer, $81 \%$ received HER2 testing, a proportion that substantially increased between 1998 and 2000 from 12\% to over 94\%. After 2000 , more than $94 \%$ of invasive breast cancer patients received HER 2 testing over all years combined. Women with both invasive and noninvasive breast cancer were more likely to be evaluated for HER2 if they were also evaluated for other tumor markers including ER status $(\mathrm{p}<0.0001)$ and nodal involvement $(\mathrm{p} \leq 0.007)$ (table 1$)$.

We manually abstracted medical charts to verify findings from the tumor registry. We estimated the KPNW protocol was not followed for $<3 \%$ of patients diagnosed since 2000, after correcting for errors. For the 11 patients diagnosed since 2000 with noninvasive breast cancer who received HER 2 testing according to the tumor registry, 10 patients had a diagnosis of DCIS. The remaining patient had no tumor stage in the medical record. We were unable to find evidence of HER 2 testing in the medical chart for 3 of the 10 DCIS patients. As such, 7 of these 10 patients were correctly identified as evaluated for 
Table 1. Characteristics of patients diagnosed with breast cancer in 1998-2007

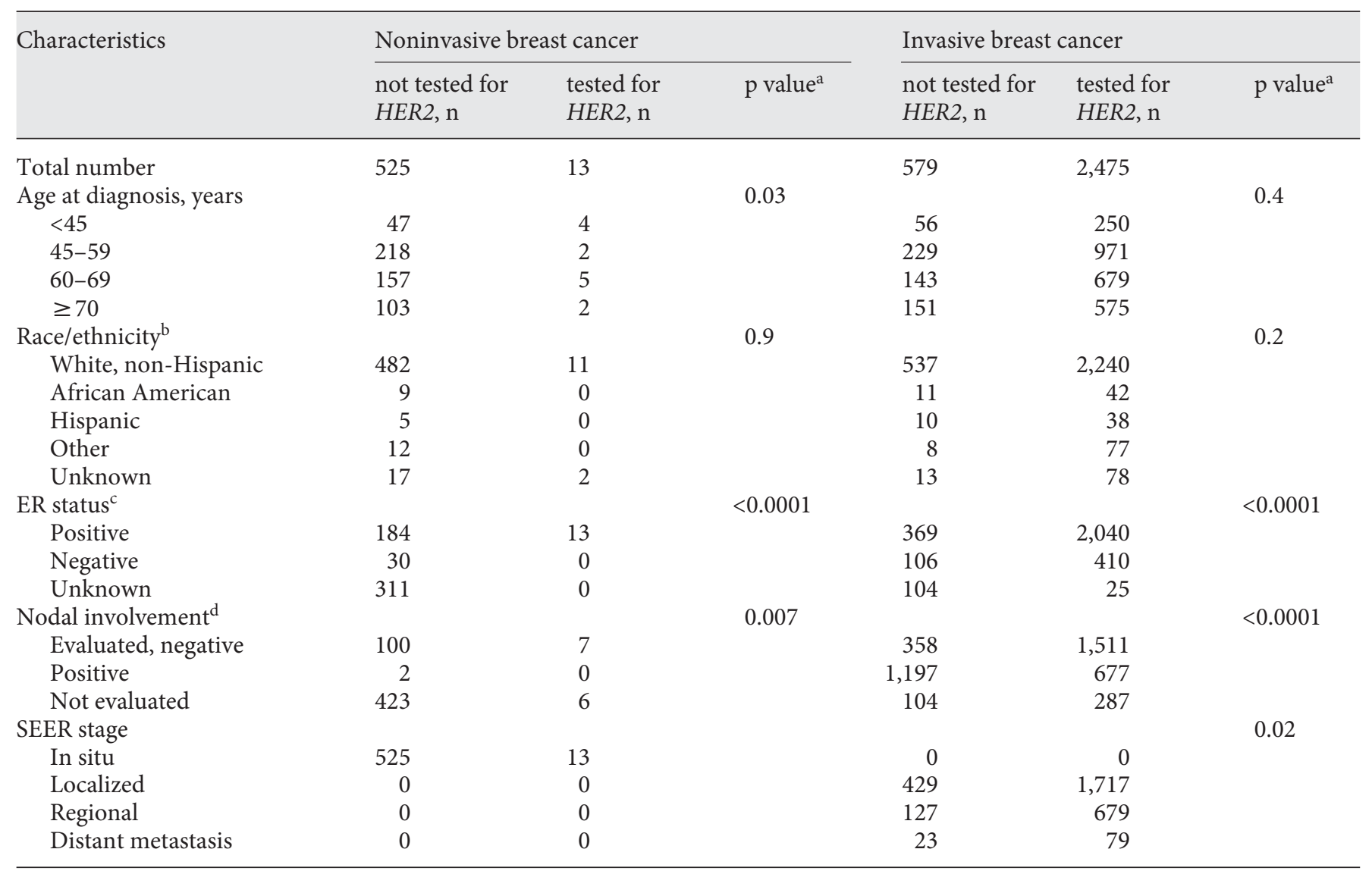

${ }^{a} \mathrm{p}$ values from Pearson's $\chi^{2}$ test with Yates' continuity correction. ${ }^{\mathrm{b}}$ The comparison is for white race versus all others. ${ }^{\mathrm{c}}$ The comparison is whether ER status is known or unknown. ${ }^{\mathrm{d}}$ The comparison is whether nodes were evaluated or not.

HER2. Thus, the tumor registry correctly identified a small number of patients with noninvasive breast cancer who received HER2 testing.

There were 154 patients diagnosed with invasive breast cancer after 1999 who did not receive HER2 testing according to the tumor registry, although they should have received this testing according to the KPNW protocol. We conducted a chart review for a random subset of 50 of these cases and discovered that $63 \%$ of the chart-reviewed cases actually did receive an IHC or FISH test. Thus, after accounting for these errors in the tumor registry, we estimate that only about $2-3 \%$ of patients with invasive breast cancer did not receive HER2 testing.

Fewer invasive breast cancer patients with Medicare/ Medicaid insurance were evaluated for HER2 compared with other insurance products $(79 \%$ vs. $83 \% ; \mathrm{p}=0.001)$ (fig. 1). Most patients (92\%) diagnosed with noninvasive breast cancer and evaluated for HER2 were treated inside
KPNW. A slightly higher proportion of patients diagnosed with invasive breast cancer and not evaluated for HER 2 were treated outside KPNW (22\% vs. $18 \%$; $\mathrm{p}=$ 0.03 ). It is possible that this difference is a result of the fact that documentation for HER2 testing was not available for some patients treated outside KPNW.

\section{Use of IHC and FISH Tests}

The majority of patients who underwent HER2 testing received the IHC test (96\%). FISH results were only recorded in the tumor registry database after 2004 (table 2). Forty-two percent of those diagnosed with invasive breast cancer between 2004 and $2007(\mathrm{n}=1,232)$ received FISH testing, and $82 \%$ (433) of these also received IHC testing. About $81 \%$ of patients who received FISH testing, but not IHC testing, were diagnosed after October 2007, when KPNW adopted FISH testing as the primary HER2 test. 
Table 2. Comparison of FISH and IHC test results for invasive breast cancer patients diagnosed after 2004

\begin{tabular}{lccccr}
\hline \multirow{2}{*}{ IHC test result } & \multicolumn{2}{l}{ FISH test result } & & & \\
\cline { 2 - 6 } & not done & negative & equivocal & positive & total \\
\hline Not done & 49 & 76 & 4 & 12 & 141 \\
Negative & 538 & 84 & 2 & 1 & 625 \\
Equivocal & 69 & 175 & 8 & 25 & 277 \\
Positive & 49 & 55 & 6 & 75 & 185 \\
Total & 705 & 390 & 20 & 113 & 1,228 \\
\hline
\end{tabular}

\section{Confirmation of IHC Results}

As table 2 shows, tumor registry data indicate inconsistent adherence to KPNW policy on FISH testing following an equivocal or positive IHC test result. However, chart review reveals better compliance. For 50 patients with an equivocal IHC test result who did not have a FISH test result in the tumor registry, chart review revealed that $88 \%$ did have a FISH test result in the medical record. Furthermore, although the KPNW protocol does not include confirmation of negative IHC test results by FISH, chart review confirmed that $88 \%$ of patients with a negative IHC test result and a FISH test result in the tumor registry did receive FISH testing. However, 12 (27\%) patients did not actually have a negative IHC test result. These findings indicate that negative IHC test results are occasionally confirmed by FISH in this setting, but also highlight some apparent discrepancies in the tumor registry.

About $40 \%$ of patients who received both tests and had a positive IHC test result were found to have the opposite finding (negative result) for the FISH test (table 2). In contrast, nearly everyone who received both tests and had a negative IHC test result was found to have a consistent negative FISH result. As discussed below, these discrepancies can impact decisions about whether to treat with trastuzumab.

\section{Does Treatment with Trastuzumab Depend on HER2}

Status?

In the entire population of patients evaluated for HER2, $14 \%$ had a positive test result (using IHC and/or FISH) (table 3). The majority (81\%) of patients who received trastuzumab had a positive HER 2 test result using IHC, FISH or both in the tumor registry. Subsequent chart review of the remaining 26 patients indicated that, in nearly all cases (95\%), patients who received trastuzumab were appropriate candidates for this therapy based

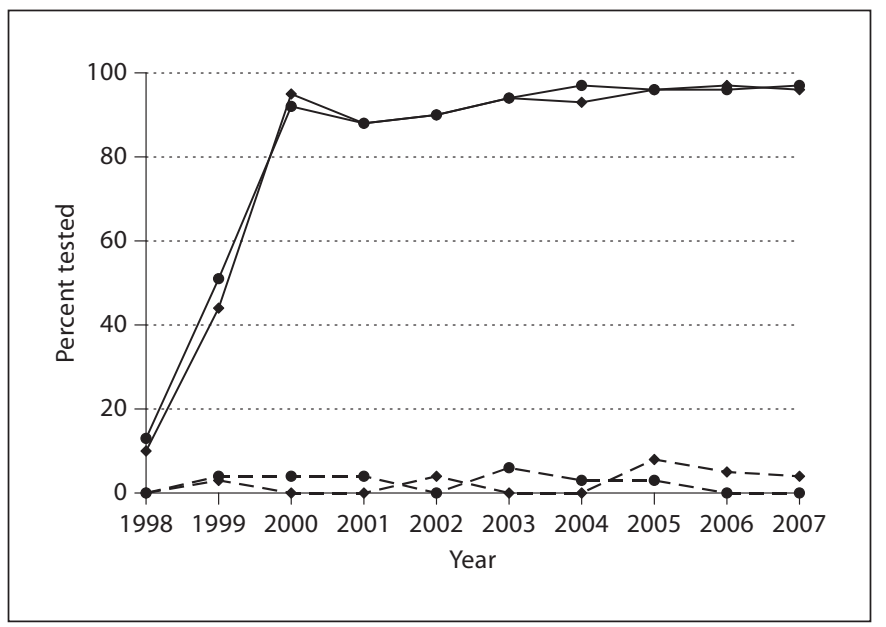

Fig. 1. Rate of HER2 testing at KPNW from 1998 to 2007. The solid lines correspond to patients diagnosed with invasive breast cancer with Medicare/Medicaid insurance (diamonds) or with other insurance (circles), and the dashed lines correspond to patients diagnosed with ductal carcinoma in situ or noninvasive breast cancer.

on their HER2 genetic test result (table 4). Overall, $<1 \%$ of patients who did not have a positive HER 2 test received trastuzumab.

Table 3 shows the proportion of patients who received trastuzumab by tumor stage and HER2 status. Prior to 2005, only $9 \%$ of HER2-positive patients received trastuzumab; the majority of treated patients had regional or metastatic disease $(88 \%)$, consistent with professional recommendations at that time. After 2004, trastuzumab use increased for all stages of disease, with an overall frequency of 55\% among HER2-positive patients, and increasing use among patients with more advanced disease (up to $80 \%$ for those with distant metastatic disease). A few patients had discordant HER2 test results for IHC 
Table 3. Use of trastuzumab among breast cancer patients diagnosed between 1998-2007

\begin{tabular}{lcclc}
\hline SEER Stage & \multicolumn{2}{l}{ HER2 positive ${ }^{\mathrm{a}},(\%)$} & $\begin{array}{l}\text { HER2 } \\
\text { discordant }^{\mathrm{b}},(\%)\end{array}$ & $\begin{array}{l}\text { HER2 negative/ } \\
\text { equivocal/unknown, (\%) }\end{array}$ \\
\cline { 2 - 5 } & $1998-2004$ & $2005-2007$ & $2004-2007$ & $1998-2007$ \\
\hline In situ & $0 / 1^{\mathrm{c}}(0)$ & $0 / 0(0)$ & $0 / 0(0)$ & $2 / 537(<1)$ \\
Localized & $4 / 220(2)$ & $35 / 79(44)$ & $1 / 31(3)$ & $12 / 1815(<1)$ \\
Regional & $20 / 123(16)$ & $28 / 41(68)$ & $0 / 23(0)$ & $10 / 619(1.6)$ \\
Distant metastasis & $11 / 22(50)$ & $8 / 10(80)$ & $1 / 2(50)$ & $2 / 68(3)$ \\
Total & $35 / 366(9)$ & $71 / 130(55)$ & $2 / 56(4)$ & $26 / 3039(0.8)$ \\
\hline
\end{tabular}

a Patients were defined as HER2 positive if they had a positive HER2 test result by either FISH or IHC or both, but not discordant HER2 results. ${ }^{\mathrm{b}}$ Patients were defined as HER2 discordant if the IHC test was positive and the FISH test was negative $(n=55)$ or the other way around $(n=1){ }^{c}$ The ratio in each cell refers to the number of patients who received trastuzumab divided by the total number of patients in that cell.

Table 4. Reasons for treatment with trastuzumab for 26 patients without a positive HER 2 test result in the electronic tumor registry file

\begin{tabular}{ll}
\hline Tumor registry result & Chart review result \\
\hline $\begin{array}{l}\text { Missing HER2 test result } \\
\text { (10 patients) }\end{array}$ & $\begin{array}{l}7 \text { patients had recurrent breast cancer with a positive HER2 test result at recur- } \\
\text { rence, although not at initial diagnosis. } 6 \text { patients were diagnosed prior to 2000 } \\
\text { before HER2 testing became systematically used at initial diagnosis. } \\
\text { 2 patients received HER2 testing outside of KPNW. } \\
1 \text { patient showed no evidence of treatment with trastuzumab. }\end{array}$ \\
\hline $\begin{array}{l}\text { Negative HER2 test result } \\
\text { (7 patients) }\end{array}$ & $\begin{array}{l}\text { 6 patients had a positive HER2 test result. } 4 \text { of these patients had multiple pri- } \\
\text { mant the one testing positive. }\end{array}$ \\
& $\begin{array}{l}1 \text { patient had an equivocal HER2 test result for both FISH and IHC, and the } \\
\text { physician decided to treat with trastuzumab. }\end{array}$ \\
\hline $\begin{array}{l}\text { Equivocal HER2 test result } \\
\text { (9 patients) }\end{array}$ & $\begin{array}{l}5 \text { patients had a positive HER2 test result. } \\
\text { In } 3 \text { patients physician notes documented a decision to treat with trastuzu- } \\
\text { mab based on the equivocal HER2 result. } \\
1 \text { patient received all treatment outside the KPNW system. }\end{array}$ \\
&
\end{tabular}

Table 5. Reasons for no treatment with trastuzumab among HER2-positive women with distant metastatic or regional (after 2004) breast cancer

\begin{tabular}{|c|c|c|c|}
\hline \multirow[t]{2}{*}{ Reason } & \multicolumn{2}{|c|}{ Distant metastatic } & \multirow{2}{*}{$\frac{\text { Regional }}{2005-2007}$} \\
\hline & $1998-2004$ & $2005-2007$ & \\
\hline Patient received trastuzumab outside KPNW & 1 & 1 & 3 \\
\hline Patient had congestive heart failure & 0 & 0 & 3 \\
\hline Patient declined or physician decided not to treat & 3 & 0 & 2 \\
\hline Unrecorded negative FISH result & 5 & 1 & 0 \\
\hline Equivocal FISH result & 1 & 0 & 2 \\
\hline No positive HER2 result found in chart review & 1 & 0 & 0 \\
\hline Unknown & 0 & 0 & 3 \\
\hline Total & 11 & 2 & 13 \\
\hline
\end{tabular}


and FISH, and these patients generally did not receive trastuzumab ( $4 \%$ received treatment). There were several reasons why women with a positive HER 2 test did not receive trastuzumab (table 5), although chart review found that 5 out of 26 women who did not receive trastuzumab according to the tumor registry actually did receive treatment outside of KPNW.

\section{Discussion}

We conducted a retrospective analysis of patients diagnosed with breast cancer between 1998 and 2007 to evaluate the utilization and treatment patterns associated with HER2 testing in an integrated healthcare delivery system. The prevalence of HER2 testing in appropriate candidates with breast cancer was very high ( $>94 \%)$ following an initial 2-year period. Trastuzumab treatment was guided by HER 2 test results in most instances (95\%), and $<1 \%$ of patients with a negative or equivocal HER 2 test result were treated with trastuzumab.

These results are important for several reasons. First, there is still a great need for research describing how sophisticated genetic tests, with potentially confusing treatment ramifications, are taken up by clinicians and whether such tests are being appropriately used in treatment. This study shows that in a large integrated managed care setting, HER 2 testing is being performed on the appropriate patients, and the results are being interpreted correctly in terms of treatment implications. Only 2 other similar studies $[53,54]$ have been done in managed care settings. Although the sample sizes for these studies were smaller, their findings were similar to ours. Stark et al. [53] conducted a study at Henry Ford Health System (Detroit, Mich., USA) between 1999 and 2000. They reported that $51.9 \%$ of women diagnosed with primary breast cancer were evaluated for HER2. Barron et al. [54] reviewed the charts of 380 patients in commercial health plans diagnosed in 2005 through mid-2006. HER2 testing occurred in $98.1 \%$ of patients with invasive breast cancer, and only one patient (out of 52) who received trastuzumab did not have a documented positive HER2 test result. For HER2-positive women diagnosed with stage 2 or higher breast cancer $(n=45), 87 \%$ received trastuzumab.

Two studies conducted in the UK have recently been reported $[55,56]$, which address similar questions in the context of a national healthcare system. In the UK, the National Institute for Health and Clinical Excellence guidance has recommended adjuvant trastuzumab for women with positive HER2 test results with normal left ventricular ejection fraction and without cardiac contraindications to trastuzumab therapy since 2005 [57]. Coulson et al. [55] evaluated patients who received HER2 testing between September 2007 and August 2008 in the North Trent Cancer Network. In this study, $15.1 \%$ of tested subjects were HER 2 positive, and $67 \%$ of HER2-positive subjects were treated with trastuzumab. The primary reasons that patients did not receive treatment were (1) age $>75$ years with or without general frailty or poor performance status, (2) patient refusal or (3) high cardiac risk. This study did not include subjects who did not receive HER2 testing. Webster et al. [56] evaluated patients diagnosed with early breast cancer during 2006-2007 in the South West Wales Cancer Network. In this study, $10.4 \%$ of tested subjects were HER 2 positive, and $13.5 \%$ did not receive HER2 testing. Patients who were not assessed for HER2 status were primarily elderly women who did not receive surgical intervention after the initial biopsy. Among the HER2-positive subjects, $72.3 \%$ received trastuzumab.

In contrast, Tong et al. [58] evaluated Medicare data for patients diagnosed with breast cancer in 2005. Only $22 \%$ of patients in that study were evaluated for HER2, and $94 \%$ of those received IHC alone, $1 \%$ received FISH alone, and $5 \%$ received both tests. Furthermore, $61 \%$ of patients who received trastuzumab were not evaluated for HER2. Stark et al. [53] also indicate that the type of health insurance (capitated insurance vs. fee-for-service [FFS]) influenced the probability of receiving HER2 testing, with an increased likelihood of testing for those with capitated insurance $(\mathrm{OR}=1.59 ; \mathrm{p}=0.027)$.

This study provides a crucial stepping stone to further research in the complex field of genomic medicine. At present, very few healthcare systems have the ability to examine the uptake and use of genetic tests on a scale large enough to evaluate them systematically. Without reliable data on how genetic tests are used to inform medical decisions, we cannot achieve the next level of genomic research. In the context of HER2 testing and treatment decisions, for example, we can now build upon the existing data to evaluate patient outcomes and adverse events that patients experience from treatment in the context of their HER2 test result.

Nevertheless, the electronic data sources employed for this study had a few limitations. For example, we did not confirm the validity of HER2 test results because this study focused on how clinician treatment decisions are influenced by evaluation of HER2, and the reported test result was the most relevant data for our research question. Additionally, we did not limit the study population 
based on membership criteria, a potential limitation since some individuals may have incomplete treatment information if they left the health plan before their treatment was complete. About $8 \%(n=299)$ of subjects in the study population had 2 years or less of membership following breast cancer diagnosis. The possibility of incomplete treatment history is particularly concerning for this group. However, when we restricted the data to only these subjects, the conclusions do not change regarding the impact of HER2 status and disease stage on trastuzumab treatment status (data not shown). About $70 \%$ of subjects have 10 years or more of membership following breast cancer diagnosis. Finally, we identified inconsistencies between the tumor registry and the results from manual chart review, which are primarily instances of missing data in the tumor registry. Since it was not feasible to manually abstract all the records in this study, we only performed targeted chart review in situations with unexpected findings.

Our findings indicate that KPNW is systematically performing HER 2 evaluation on patients with invasive breast cancers, and the information is used to make treatment decisions. The presence of an integrated, highlyutilized and well-established electronic medical record has likely improved communication of test results between pathologists (who order/perform the test) and on- cologists, who make treatment recommendations. While it is unknown whether the findings of this study are widely applicable beyond managed care settings, about $25 \%$ of Americans receive healthcare in a managed care setting [59], and these findings are directly relevant to this substantial minority of the population. These questions should be addressed in other settings for comparison, as part of an assessment for implementation research.

\section{Acknowledgements}

The authors would like to thank Dr. Mona Ishag from the KPNW Department of Pathology and Dr. Mark Hornbrook from the Center for Health Research for their careful review and comments during the preparation of the manuscript. This work was partially supported by resources developed through a grant from the National Cancer Institute (U19 CA 79689). This research was conducted at a single site of the HMO Cancer Research Network (CRN). The CRN consists of the research programs, enrollee populations and databases of 14 HMO members of the HMO Research Network. The overall goal of the CRN is to conduct collaborative research to determine the effectiveness of preventive, curative and supportive interventions for major cancers that span the natural history of those cancers among diverse populations and health systems. The 14 health plans, with nearly 11 million enrollees are distinguished by their longstanding commitment to prevention and research, and collaboration among themselves and with affiliated academic institutions.

\section{References}

1 Jemal A, Siegel R, Ward E, Murray T, Xu J, Thun MJ: Cancer statistics, 2007. CA Cancer J Clin 2007;57:43-66.

2 American Cancer Society: Cancer facts \& figures 2009. Atlanta, 2009. http://www. scribd.com/doc/21686287/Cancer-Factsand-Figures-Report-2009.

-3 Phillips KA: Closing the evidence gap in the use of emerging testing technologies in clinical practice. JAMA 2008;300:2542-2544.

4 Phillips KA, Liang SY, Van BS: Challenges to the translation of genomic information into clinical practice and health policy: utilization, preferences and economic value. Curr Opin Mol Ther 2008;10:260-266.

5 Slamon DJ, Clark GM, Wong SG, Levin WJ, Ullrich A, McGuire WL: Human breast cancer: correlation of relapse and survival with amplification of the HER-2/neu oncogene. Science 1987;235:177-182.

-6 Yaziji H, Goldstein LC, Barry TS, Werling R, Hwang H, Ellis GK, Gralow JR, Livingston $\mathrm{RB}$, Gown AM: HER-2 testing in breast cancer using parallel tissue-based methods. JAMA 2004;291:1972-1977.
Owens MA, Horten BC, Da Silva MM: HER2 amplification ratios by fluorescence in situ hybridization and correlation with immunohistochemistry in a cohort of 6556 breast cancer tissues. Clin Breast Cancer 2004;5:63-69.

8 Press M, Pike M, Chazin V, Hung G, Udove JA, Markowicz M, Danyluk J, Godolphin W, Sliwkowski M, Akita R, et al: HER-2/neu expression in node-negative breast cancer: direct tissue quantitation by computerized image analysis and association of overexpression with increased risk of recurrent disease. Cancer Res 1993;53:4960-4970.

-9 Press MF, Bernstein L, Thomas PA, Meisner LF, Zhou JY, Ma Y, Hung G, Robinson RA, Harris C, El-Naggar A, Slamon DJ, Phillips RN, Ross JS, Wolman SR, Flom KJ: HER-2/ neu gene amplification characterized by fluorescence in situ hybridization: poor prognosis in node-negative breast carcinomas. J Clin Oncol 1997;15:2894-2904.

10 Yamauchi H, Stearns V, Hayes DF: When is a tumor marker ready for prime time? A case study of $c$-erbB-2 as a predictive factor in breast cancer. J Clin Oncol 2001;19:23342356.
11 Slamon D, Elermann W, Robert N, et al: Phase III randomized trial comparing doxorubicin and cyclophosphamide followed by docetaxel (ACT) with doxorubicin and cyclophosphamide followed by doxorubicin and trastuzumab (ACTH) with doxorubicin, carboplatin and trastuzumab (TCH) in HER2 positive early breast cancer patients: BCIRG 006 study (abstract 62). Breast Cancer Res Treat 2005;94(suppl 1):S5.

12 Joensuu H, Kellokumpu-Lehtinen PL, Bono P, Alanko T, Kataja V, Asola R, Utriainen T, Kokko R, Hemminki A, Tarkkanen M, Turpeenniemi-Hujanen T, Jyrkkiö S, Flander M, Helle L, Ingalsuo S, Johansson K, Jääskeläinen AS, Pajunen M, Rauhala M, Kaleva-Kerola J, Salminen T, Leinonen M, Elomaa I, Isola J; FinHer Study Investigators: Adjuvant docetaxel or vinorelbine with or without trastuzumab for breast cancer. N Engl J Med 2006;354:809-820. 
$\checkmark 13$ Romond EH, Perez EA, Bryant J, Suman VJ, Geyer CE, Jr., Davidson NE, Tan-Chiu E, Martino S, Paik S, Kaufman PA, Swain SM, Pisansky TM, Fehrenbacher L, Kutteh LA, Vogel VG, Visscher DW, Yothers G, Jenkins RB, Brown AM, Dakhil SR, Mamounas EP, Lingle WL, Klein PM, Ingle JN, Wolmark N: Trastuzumab plus adjuvant chemotherapy for operable HER2-positive breast cancer. $\mathrm{N}$ Engl J Med 2005;353:1673-1684.

14 Piccart-Gebhart MJ, Procter M, LeylandJones B, Goldhirsch A, Untch M, Smith I, Gianni L, Baselga J, Bell R, Jackisch C, Cameron D, Dowsett M, Barrios CH, Steger G, Huang CS, Andersson M, Inbar M, Lichinitser M, Láng I, Nitz U, Iwata H, Thomssen C, Lohrisch C, Suter TM, Rüschoff J, Suto T, Greatorex V, Ward C, Straehle C, McFadden E, Dolci MS, Gelber RD; Herceptin Adjuvant (HERA) Trial Study Team: Trastuzumab after adjuvant chemotherapy in HER2-positive breast cancer. N Engl J Med 2005;353: 1659-1672.

15 The HERA Study Team: Trastuzumab following adjuvant chemoptherapy in HER2positive early stage breast cancer (HERA trial): disease-free and overall survival after 2 year follow-up. 42nd Annual Meeting of the American Society of Clinical Oncology, Atlanta, June 2006.

-16 Liberato NL, Marchetti M, Barosi G: Cost effectiveness of adjuvant trastuzumab in human epidermal growth factor receptor 2-positive breast cancer. J Clin Oncol 2007;25:625-633.

-17 Kurian AW, Thompson RN, Gaw AF, Arai S, Ortiz R, Garber AM: A cost-effectiveness analysis of adjuvant trastuzumab regimens in early HER2/neu-positive breast cancer. J Clin Oncol 2007;25:634-641.

- 18 Tan-Chiu E, Yothers G, Romond E, Geyer CE, Jr., Ewer M, Keefe D, Shannon RP, Swain SM, Brown A, Fehrenbacher L, Vogel VG, Seay TE, Rastogi P, Mamounas EP, Wolmark $\mathrm{N}$, Bryant J: Assessment of cardiac dysfunction in a randomized trial comparing doxorubicin and cyclophosphamide followed by paclitaxel, with or without trastuzumab as adjuvant therapy in node-positive, human epidermal growth factor receptor 2-overexpressing breast cancer: NSABP B-31. J Clin Oncol 2005;23:7811-7819.

19 Slamon DJ, Leyland-Jones B, Shak S, Fuchs $\mathrm{H}$, Paton V, Bajamonde A, Fleming T, Eiermann W, Wolter J, Pegram M, Baselga J, Norton L: Use of chemotherapy plus a monoclonal antibody against HER2 for metastatic breast cancer that overexpresses HER2. N Engl J Med 2001;344:783-792.

20 Cobleigh MA, Vogel CL, Tripathy D, Robert NJ, Scholl S, Fehrenbacher L, Wolter JM, Paton V, Shak S, Lieberman G, Slamon DJ: Multinational study of the efficacy and safety of humanized anti-HER2 monoclonal antibody in women who have HER2-overexpressing metastatic breast cancer that has progressed after chemotherapy for metastatic disease. J Clin Oncol 1999;17:2639-2648.
21 Vogel CL, Cobleigh MA, Tripathy D, Gutheil JC, Harris LN, Fehrenbacher L, Slamon DJ, Murphy M, Novotny WF, Burchmore M, Shak S, Stewart SJ, Press M: Efficacy and safety of trastuzumab as a single agent in first-line treatment of HER2-overexpressing metastatic breast cancer. J Clin Oncol 2002; 20:719-726.

22 FDA/CBER. Trastuzumab: Clinical review briefingdocumentsBLASTN:103792\5008\D [Original BLA 99-0369]. FDA/CBER 2007. http://www.fdagov/ohrms/dockets/ac/01/ briefing/3815b1_08_HER2\%20FISH.pdf.

23 Mass RD, Press MF, Anderson S, Cobleigh MA, Vogel CL, Dybdal N, Leiberman G, Slamon DJ: Evaluation of clinical outcomes according to HER2 detection by fluorescence in situ hybridization in women with metastatic breast cancer treated with trastuzumab. Clin Breast Cancer 2005;6:240-246.

24 Bartlett JM, Going JJ, Mallon EA, Watters AD, Reeves JR, Stanton P, Richmond J, Donald B, Ferrier R, Cooke TG: Evaluating HER2 amplification and overexpression in breast cancer. J Pathol 2001;195:422-428.

25 Wolff AC, Hammond ME, Schwartz JN, Hagerty KL, Allred DC, Cote RJ, Dowsett M, Fitzgibbons PL, Hanna WM, Langer A, McShane LM, Paik S, Pegram MD, Perez EA, Press MF, Rhodes A, Sturgeon C, Taube SE, Tubbs R, Vance GH, van de Vijver M, Wheeler TM, Hayes DF; American Society of Clinical Oncology; College of American Pathologists: American Society of Clinical Oncology/College of American Pathologists guideline recommendations for human epidermal growth factor receptor 2 testing in breast cancer. J Clin Oncol 2007;25:118-145.

-26 Borg A, Baldetorp B, Ferno M, Killander D, Olsson H, Rydén S, Sigurdsson H: ERBB2 amplification is associated with tamoxifen resistance in steroid-receptor positive breast cancer. Cancer Lett 1994;81:137-144.

27 Sjogren S, Inganas M, Lindgren A, Holmberg $\mathrm{L}$, Bergh J: Prognostic and predictive value of c-erbB-2 overexpression in primary breast cancer, alone and in combination with other prognostic markers. J Clin Oncol 1998; 16: 462-469.

28 Carlomagno C, Perrone F, Gallo C, De Laurentiis M, Lauria R, Morabito A, Pettinato G, Panico L, D'Antonio A, Bianco AR, De Placido S: c-erb B2 overexpression decreases the benefit of adjuvant tamoxifen in early-stage breast cancer without axillary lymph node metastases. J Clin Oncol 1996;14:2702-2708.

29 De Placido S, De Laurentiis M, Carlomagno C, Gallo C, Perrone F, Pepe S, Ruggiero A, Marinelli A, Pagliarulo C, Panico L, Pettinato $G$, Petrella G, Bianco AR: Twenty-year results of the Naples GUN randomized trial: predictive factors of adjuvant tamoxifen efficacy in early breast cancer. Clin Cancer Res 2003;9:1039-1046.
30 Ellis MJ, Coop A, Singh B, Mauriac L, Llombert-Cussac A, Jänicke F, Miller WR, Evans DB, Dugan M, Brady C, Quebe-Fehling E, Borgs M: Letrozole is more effective neoadjuvant endocrine therapy than tamoxifen for ErbB-1- and/or ErbB-2-positive, estrogen receptor-positive primary breast cancer: evidence from a phase III randomized trial. J Clin Oncol 2001;19:3808-3816.

-31 Knoop AS, Bentzen SM, Nielsen MM, Rasmussen BB, Rose C: Value of epidermal growth factor receptor, HER2, p53, and steroid receptors in predicting the efficacy of tamoxifen in high-risk postmenopausal breast cancer patients. J Clin Oncol 2001;19: 3376-3384.

32 Berry DA, Muss HB, Thor AD, Dressler L, Liu ET, Broadwater G, Budman DR, Henderson IC, Barcos M, Hayes D, Norton L: HER$2 /$ neu and p53 expression versus tamoxifen resistance in estrogen receptor-positive, node-positive breast cancer. J Clin Oncol 2000;18:3471-3479.

33 Wood WC, Budman DR, Korzun AH, Cooper MR, Younger J, Hart RD, Moore A, Ellerton JA, Norton L, Ferree CR, et al: Dose and dose intensity of adjuvant chemotherapy for stage II, node-positive breast carcinoma. N Engl J Med 1994;330:1253-1259.

34 Budman DR, Berry DA, Cirrincione CT, Henderson IC, Wood WC, Weiss RB, Ferree CR, Muss HB, Green MR, Norton L, Frei E 3rd: Dose and dose intensity as determinants of outcome in the adjuvant treatment of breast cancer. The Cancer and Leukemia Group B. J Natl Cancer Inst 1998;90:12051211.

- 35 Stal O, Borg A, Ferno M, Kallstrom AC, Malmstrom P, Nordenskjold B: ErbB2 status and the benefit from two or five years of adjuvant tamoxifen in postmenopausal early stage breast cancer. Ann Oncol 2000;11: 1545-1550.

-36 Love RR, Duc NB, Havighurst TC, Mohsin SK, Zhang Q, DeMets DL, Allred DC: Her-2/ neu overexpression and response to oophorectomy plus tamoxifen adjuvant therapy in estrogen receptor-positive premenopausal women with operable breast cancer. J Clin Oncol 2003;21:453-457.

37 De Laurentiis M, Arpino G, Massarelli E, Ruggiero A, Carlomagno C, Ciardiello F, Tortora G, D'Agostino D, Caputo F, Cancello G, Montagna E, Malorni L, Zinno L, Lauria R, Bianco AR, De Placido S: A meta-analysis on the interaction between HER-2 expression and response to endocrine treatment in advanced breast cancer. Clin Cancer Res 2005; 11:4741-4748.

38 Thor AD, Berry DA, Budman DR, Muss HB, Kute T, Henderson IC, Barcos M, Cirrincione C, Edgerton S, Allred C, Norton L, Liu ET: erbB-2, p53, and efficacy of adjuvant therapy in lymph node-positive breast cancer. J Natl Cancer Inst 1998;90:1346-1360. 
-39 Del Mastro L, Bruzzi P, Nicolò G, Cavazzini G, Contu A, D’Amico M, Lavarello A, Testore F, Castagneto B, Aitini E, Perdelli L, Bighin C, Rosso R, Venturini M: HER2 expression and efficacy of dose-dense anthracycline-containing adjuvant chemotherapy in breast cancer patients. Br J Cancer 2005;93: 7-14.

40 Paik S, Bryant J, Park C, Fisher B, Tan-Chiu E, Hyams D, Fisher ER, Lippman ME, Wickerham DL, Wolmark N: erbB-2 and response to doxorubicin in patients with axillary lymph node-positive, hormone receptornegative breast cancer. J Natl Cancer Inst 1998;90:1361-1370.

41 Ravdin P, Green S, Albain K, et al: Initial report of the SWOG biological correlative study of $c$-erB-2 expression as a predictor of outcome in a trial comparing, adjuvant $\mathrm{CAF}$ $\mathrm{T}$ with tamoxifen ( $\mathrm{T}$ ) alone (abstract 374 ). Proc Am Soc Clin Oncol 1998; 17:97a.

42 Albain K, Green S, Osborne K, Cobau C, Levine E, Ingle J, Pritchard K, Schneider D, O'Sullivan J, Hess E, et al: Tamoxifen (T) versus cyclophosphamide, adriamycin, and $5 \mathrm{FU}$ plus either concurrent or sequential $\mathrm{T}$ in postmenopausal receptor positive, node positive breast cancer: a Southwest Onclology Group Phase III Intergroup Trial (abstract 450). Proc Am Soc Clin Oncol 1997; 16:128a.

-43 Paik S, Bryant J, Tan-Chiu E, Yothers G, Park C, Wickerham DL, Wolmark N: HER2 and choice of adjuvant chemotherapy for invasive breast cancer: National Surgical Adjuvant Breast and Bowel Project Protocol B-15. J Natl Cancer Inst 2000;92:1991-1998.

-44 Pritchard KI, Shepherd LE, O’Malley FP, Andrulis IL, Tu D, Bramwell VH, Levine MN; National Cancer Institute of Canada Clinical Trials Group: HER2 and responsiveness of breast cancer to adjuvant chemotherapy. N Engl J Med 2006;354:2103-2111.
45 Zhang F, Yang Y, Smith T, Kau SW, McConathy JM, Esteva FJ, Kuerer HM, Symmans WF, Buzdar AU, Hortobagyi GN, Pusztai L: Correlation between HER-2 expression and response to neoadjuvant chemotherapy with 5-fluorouracil, doxorubicin, and cyclophosphamide in patients with breast carcinoma. Cancer 2003;97:1758-1765.

46 Carlson RW, Moench SJ, Hammond ME, Perez EA, Burstein HJ, Allred DC, Allred DC, Vogel CL, Goldstein LJ, Somlo G, Gradishar WJ, Hudis CA, Jahanzeb M, Stark A, Wolff AC, Press MF, Winer EP, Paik S, Ljung BM; NCCN HER2 Testing in Breast Cancer Task Force: HER2 testing in breast cancer: NCCN Task Force report and recommendations. J Natl Compr Canc Netw 2006;4(suppl 3):S1-22.

47 Carlson RW, Anderson BO, Bensinger W, Cox CE, Davidson NE, Edge SB, Farrar WB, Goldstein LJ, Gradishar WJ, Lichter AS, McCormick B, Nabell LM, Reed EC, Silver SM, Smith ML, Somlo G, Theriault R, Ward JH, Winer EP, Wolff A; National Comprehensive Cancer Network: NCCN Practice Guidelines for Breast Cancer. Oncology (Williston Park) 2000;14:33-49.

48 Update: NCCN practice guidelines for the treatment of breast cancer. National Comprehensive Cancer Network. Oncology (Williston Park) 1999;13:41-66.

49 Carlson RW: NCCN breast cancer clinical practice guidelines in oncology: an update. J Natl Compr Canc Netw 2003;1(suppl 1): S61-S63.

50 Carlson RW, Allred DC, Anderson BO, Burstein HJ, Carter WB, Edge SB, Erban JK, Farrar WB, Goldstein LJ, Gradishar WJ, Hayes DF, Hudis CA, Jahanzeb M, Kiel K, Ljung BM, Marcom PK, Mayer IA, McCormick B, Nabell LM, Pierce LJ, Reed EC, Smith ML, Somlo G, Theriault RL, Topham NS, Ward JH, Winer EP, Wolff AC; NCCN Breast Cancer Clinical Practice Guidelines Panel: Breast cancer. Clinical practice guidelines in oncology. J Natl Compr Canc Netw 2009; 7:122-192.

-51 Thwin SS, Clough-Gorr KM, McCarty MC, Lash TL, Alford SH, Buist DS, Enger SM, Field TS, Frost F, Wei F, Silliman RA: Automated inter-rater reliability assessment and electronic data collection in a multi-center breast cancer study. BMC Med Res Methodol 2007;7:23.
52 Young JL Jr, Roffers SD, Ries LAG, Fritz AG, Hurlbut AA (eds): SEER Summary Staging Manual - 2000: Codes and Coding Instructions. National Cancer Institute, NIH Pub No. 01-4969, Bethesda, 2001.

53 Stark A, Kucera G, Lu M, Claud S, Griggs J: Influence of health insurance status on inclusion of HER-2/neu testing in the diagnostic workup of breast cancer patients. Int J Qual Health Care 2004;16:517-521.

54 Barron JJ, Cziraky MJ, Weisman T, Hicks DG: HER2 testing and subsequent trastuzumab treatment for breast cancer in a managed care environment. Oncologist 2009;14: $760-768$.

55 Coulson SG, Kumar VS, Manifold IM, Hatton MQ, Ramakrishnan S, Dunn KS, Purohit OP, Bridgewater C, Coleman RE: Review of testing and use of adjuvant trastuzumab across a cancer network-are we treating the right patients? Clin Oncol (R Coll Radiol) 2010;22:289-293.

56 Webster R, Palaniappan N, Abraham J, Bertelli G, Jasani B, Barrett-Lee P: HER2 testing, adjuvant trastuzumab use and results. Our experience in South Wales. Clin Oncol (R Coll Radiol) 2010;22:894.

57 National Institute for Health and Clinical Excellence: Trastuzumab for the adjuvant treatment of early-stage HER2-positive breast cancer. Technology appraisal TA109. London, NICE, September 2006.

58 Tong KB, Chen E, Gregory C, Kim D: HER-2 testing and trastuzumab use in the Medicare population (abstract 141). Breast Cancer Symposium, San Francisco, September 2007. www.asco.org/ASCOv2/meetings/Abstracts ?\&vmview=abst_detail_view\&confID $=52$ \& abstractID $=40386$ (accessed September 25, 2009).

59 National Center for Health Statistics: Health, United States, 2007. With Chartbook on Trends in the Health of Americans, table 150. Hyattsville, MD, 2007. 